\title{
COMPACTAÇÃO DO SOLO E PRODUÇÃO DE CULTIVARES DE MILHO EM LATOSSOLO VERMELHO. II - INTERVALO HÍDRICO ÓTIMO E SISTEMA RADICULAR ${ }^{(1)}$
}

\author{
Onã da Silva Freddi ${ }^{(2)}$, José Frederico Centurion ${ }^{(3)}$, Aildson Pereira \\ Duarte $^{(4)} \&$ Fernanda Salles Cunha Peres ${ }^{(5)}$
}

\begin{abstract}
RESUMO
Este trabalho teve como objetivo avaliar, no campo, a resposta de duas cultivares de milho em um Latossolo Vermelho, em seis níveis de compactação, quanto ao desenvolvimento do sistema radicular, bem como caracterizar a compactação do solo a partir do intervalo hídrico ótimo (IHO). O experimento foi realizado em faixas, no delineamento de blocos completos casualizados, com quatro repetições. Utilizaram-se os híbridos de milho DKB 390 e DAS 2B710. Após a semeadura do milho, coletaram-se amostras indeformadas de solo para a determinação de propriedades físicas do solo e do IHO. No estádio do pendoamento do milho, retiraram-se três amostras por parcela na entrelinha, nas profundidades de 0-10, 10-20 e 20-30 cm, em cada parcela, para determinação de diâmetro médio, densidade do comprimento radicular e massa de matéria seca das rázes. O IHO foi igual a zero quando o solo atingiu a densidade crítica de $1,46 \mathrm{~kg} \mathrm{dm}^{-3}$, correspondente a $92 \%$ da densidade máxima do solo. Com a compactação, houve aumento da produção de matéria seca das raízes, da densidade do comprimento radicular e do diâmetro radicular e na profundidade de $\mathbf{0}-10 \mathrm{~cm}$, o aumento da massa de matéria seca e da densidade radicular se dá até a resistência do solo à penetração de 1,23 e 1,43 MPa, respectivamente. Houve correlação negativa entre a massa de matéria seca, a densidade e o diâmetro radicular com a produtividade do milho irrigado, mostrando que essas variáveis são bons indicadores da compactação do solo.
\end{abstract}

Termos de indexação: resistência do solo à penetração, conteúdo de água, sistema radicular, Zea mays.

\footnotetext{
(1) Parte da Tese de Pós-Doutorado do primeiro autor. Recebido para publicação em julho de 2008 e aprovado em maio de 2009.

(2) Pós-Doutorando da Faculdade de Ciências Agrárias e Veterinárias, Universidade Estadual Paulista - UNESP. Departamento de Solos e Adubos. Via de Acesso Prof. Paulo Donato Castellane s/n, CEP 14884-900 Jaboticabal (SP). Bolsista FAPESP. Email: onafreddi@gmail.com

${ }^{(3)}$ Professor Adjunto, Departamento de Solos e Adubos. Faculdade de Ciências Agrárias e Veterinárias, UNESP. Bolsista CNPq. E-mail: jfcentur@fcav.unesp.br

(4) Pesquisador da APTA Regional Médio Paranapanema. CEP 19802-970 Assis (SP). E-mail: aildson@aptaregional.sp.gov.br

(5) Mestre em Agronomia pela Faculdade de Ciências Agrárias e Veterinárias, UNESP. E-mail: fernandasallesc@gmail.com
} 


\title{
SUMMARY: SOIL COMPACTION AND YIELD OF CORN HYBRIDS IN AN OXISOL. II - LEAST LIMITING WATER RANGE AND ROOT SYSTEM
}

\begin{abstract}
The objective of this study was to evaluate, under field conditions, in Colina-SP, Brazil, the response of two corn cultivars to six soil compaction levels of an Oxisol regarding the root system development, and to characterize soil compaction by the least limiting water range (LLWR). The experiment was arranged in a randomized complete block design, with strip plots and four replications. The corn hybrids DKB 390 and DAS $2 B 710$ were used. After corn sowing, undisturbed soil samples were collected to determine physical properties and LLWR. At the tasseling stage of the corn plants, three soil samples per plot were taken from the crop inter-row, from the layers $0-10,10-20$ and $20-30 \mathrm{~cm}$, to measure mean root diameter, length density and dry mass. The LLWR was equal to zero when soil density reached the critical level of $1.46 \mathrm{t} \mathrm{m}^{-3}$, corresponding to $92 \%$ of the maximum soil density. Greater soil compaction resulted in greater root dry mass, length density, and diameter. In the 0-10 cm layer an increase in root dry mass and density was possible up to a penetration resistance of 1.23 MPa and 1.43 MPa, respectively. Root dry mass, density and diameter were negatively correlated with the yield of irrigated corn, and therefore represent good soil compaction indicators.
\end{abstract}

Index terms: resistance to penetration, water content, root system, Zea mays.

\section{INTRODUÇÃO}

O desenvolvimento do sistema radicular das plantas é influenciado por vários atributos físicos do solo, que governam diretamente a disponibilidade de água e nutrientes, as trocas gasosas e a resistência do solo à penetração. Contudo, devido às complexas interações que envolvem esses atributos, há dificuldade de determinar, de maneira isolada, os seus valores críticos que são limitantes ao crescimento e à produtividade das culturas.

Por esse motivo, novas determinações têm sido propostas para avaliar a qualidade dos solos, como o Intervalo Hídrico Ótimo (IHO) (Silva et al., 1994; Tormena et al., 1998). Essa medida é um indicador da qualidade física e estrutural do solo para o crescimento das plantas, pois engloba diversos fatores, como a disponibilidade de água, a aeração e a resistência do solo à penetração.

Vários trabalhos têm sido realizados para avaliar e melhorar o conceito de IHO (Araujo et al., 2004; Beutler et al., 2004, 2006). Muitos fazem referência aos limites dos atributos físicos do solo considerados restritivos, verificando suas relações com o crescimento das plantas, ou até mesmo propondo novos valores (Beutler et al., 2007; Klein \& Camara, 2007). Os valores clássicos desses limites são: $10 \%$ para a porosidade de aeração; a capacidade de campo é o conteúdo de água retida a $100 \mathrm{hPa} ; 2 \mathrm{MPa}$ para a resistência do solo à penetração; e o conteúdo de água no ponto de murcha permanente é determinado a $15.000 \mathrm{hPa}$.

Segundo Beutler et al. (2004), o valor de resistência do solo à penetração de $2 \mathrm{MPa}$ - aceito como limitante ao crescimento das raízes e da parte aérea - tem sido questionado para as diversas culturas e classes de solo sob diferentes sistemas de manejo, indicando a necessidade de mais estudos que relacionem o IHO com a produção das culturas em solos sob influência de elevado intemperismo, como os do Brasil.

Assim, Klein \& Camara (2007) verificaram que a resistência do solo à penetração de $2 \mathrm{MPa}$ não foi limitante para a soja em um Latossolo Vermelho sob plantio direto e plantio direto escarificado, pois constataram que durante praticamente todo o ciclo da cultura, em diversas profundidades, o conteúdo de água no solo permaneceu fora do IHO, quando assumido esse valor de resistência do solo à penetração. Beutler et al. (2007) utilizaram como limites de resistência do solo à penetração para a soja, em cultivo de sequeiro e irrigado, os valores de 1,3 e 1,6 MPa, respectivamente. Esses limites foram determinados no conteúdo de água retida na capacidade de campo, a partir do decréscimo de produtividade da cultura, por meio de equações de regressão.

Segundo Kay (1990), quanto menor a amplitude do IHO, maior a probabilidade de ocorrência de limitações físicas ao crescimento das raízes e plantas. Beutler et al. (2004) constataram que o IHO foi maior em um Latossolo Vermelho argiloso comparado a um Latossolo Vermelho textura média. Dessa forma, o IHO é uma ferramenta que pode ser usada por agricultores e técnicos em sistemas de produção irrigados, visando à manutenção do conteúdo de água no solo em níveis que não apresentem déficit hídrico e quando a resistência do solo à penetração e a aeração não sejam limitantes. Pode ser usado também para recomendar operações de preparo do solo, quando necessário, para aliviar problemas de compactação, indicada pela densidade crítica do solo (Benjamin et al., 2003). Para isso, é necessário estabelecer os limites críticos dos atributos do solo para as culturas.

O objetivo deste trabalho foi avaliar, em campo, a resposta de duas cultivares de milho, em um Latossolo 
Vermelho submetido a diferentes níveis de compactação, quanto às características do sistema radicular, bem como caracterizar a compactação do solo a partir do IHO.

\section{MATERIAL E MÉTODOS}

O experimento foi realizado em Colina (SP), situada nas coordenadas geográficas de $20^{\circ} 43$ ' 29 ” de latitude sul e $48^{\circ} 34^{\prime} 26^{\prime \prime}$ de longitude oeste, com altitude média de $599 \mathrm{~m}$.

O solo utilizado é um Latossolo Vermelho distrófico típico textura média hipoférrico muito profundo revelo suave ondulado (Typic Haplustox), irrigado por sistema de pivô central. Antes da instalação do experimento, foi realizada a escarificação do solo até $30 \mathrm{~cm}$ de profundidade, seguida de uma gradagem leve.

$\mathrm{O}$ experimento foi conduzido em faixas no delineamento de blocos completos casualizados, com quatro repetições. Os tratamentos foram constituídos pela combinação de seis níveis de compactação do solo e duas cultivares de milho.

Os níveis de compactação foram assim estabelecidos: $\mathrm{T} 1=$ solo preparado (escarificação e gradagem), sem tráfego de tratores; $\mathrm{T} 2=$ uma passada do trator de $4 \mathrm{t}$; T3= uma passada do trator de $6 \mathrm{t}$; $\mathrm{T} 4=$ duas passadas do trator de $6 \mathrm{t} ; \mathrm{T} 5=$ quatro passadas do trator de 6 t; e T6 = oito passadas do trator de 6 t, no sentido do declive da área, uma ao lado da outra, ou seja, repetindo-se essa operação até completar toda a superfície do solo, que apresentava conteúdo de água na capacidade de campo $\left(0,17 \mathrm{~kg} \mathrm{~kg}^{-1}\right)$. As cultivares foram semeadas em sentido perpendicular dos tratamentos de compactação.

$\mathrm{O}$ controle da irrigação foi feito por meio de seis baterias de tensiômetros instaladas nos tratamentos T1 e T6; cada bateria foi composta por três tensiômetros nas profundidades de 10, 20 e $30 \mathrm{~cm}$. Quando a média entre as leituras dos tensiômetros de decisão $(20 \mathrm{~cm})$ foi próxima ao valor da tensão de água no solo de $400 \mathrm{hPa}$, utilizou-se a irrigação para elevar essa tensão para a capacidade de campo (100 hPa).

No dia 10 de maio foram semeados, utilizando-se uma semeadora de plantio direto, os híbridos simples de milho (Zea mays L.) DKB 390, da empresa DEKALB, e DAS 2B710, da empresa Dow AgroScience, no espaçamento de $0,85 \mathrm{~m}$ entrelinhas.

Após a semeadura do milho, foram coletados em duas trincheiras, por nível de compactação, conjuntos de sete amostras indeformadas de solo, com cilindros de $54,28 \mathrm{~cm}^{3}$ ( $3 \mathrm{~cm}$ de altura e $4,8 \mathrm{~cm}$ de diâmetro), no centro das profundidades de $0-10,10-20$ e 20 $30 \mathrm{~cm}$, totalizando 42 amostras por nível de compactação e 252 amostras no experimento, para determinação dos atributos e indicadores físicos do solo. Para determinar a curva de retenção de água, foi adotado o procedimento descrito em Silva et al. (1994). As amostras foram divididas em sete grupos de 36 cilindros, sendo duas amostras por nível de compactação e por profundidade do solo, em cada tensão. Após devidamente preparadas, as amostras com estrutura não deformada foram saturadas por ascensão capilar em uma bandeja e, então, submetidas às tensões de 10, 60, 100, 330, 600, 1.000 e $3.000 \mathrm{hPa}$, em câmaras de Richards (Klute, 1986). Ao atingirem o equilíbrio, as amostras indeformadas foram pesadas, determinando-se a resistência do solo à penetração (RP) com duas repetições por amostra, na profundidade de 1 a $2 \mathrm{~cm}$, perfazendo 100 leituras por repetição, as quais foram utilizadas para obtenção da RP média de cada cilindro. A RP foi determinada por meio de um penetrômetro eletrônico estático com velocidade constante de penetração de $1 \mathrm{~cm} \mathrm{~min}{ }^{-1}$, cone com ângulo de $30^{\circ}$ e com área da base de $4,909 \mathrm{~cm}^{2}$, equipado com atuador linear e célula de carga de $20 \mathrm{~kg}$ acoplada a um microcomputador para aquisição dos dados, conforme descrito por Tormena et al. (1998). $\mathrm{Na}$ sequência, as amostras foram secas em estufa a $105^{\circ} \mathrm{C}$, durante $24 \mathrm{~h}$, para determinação do conteúdo de água em cada tensão (Gardner, 1986) e densidade do solo (Blake \& Hartge, 1986). A microporosidade foi determinada por secagem em câmaras de pressão de Richards com placa porosa (Klute, 1986) na tensão de $100 \mathrm{hPa}$; a porosidade total, segundo Danielson \& Sutherland (1986); e a macroporosidade, obtida por diferença entre a porosidade total e a microporosidade determinada na tensão de $100 \mathrm{hPa}$. As propriedades físicas do solo de cada tratamento encontram-se no quadro 1.

Se uma amostra de solo, inicialmente saturada, sofrer drenagem por etapas, e o volume de água extraído for medido para cada etapa, torna-se possível comparar o volume de água removido com o volume de poros drenados em cada tensão correspondente ao volume de vazios da amostra indeformada na tensão desejada (Ribeiro, 2005). Logo, subtraindo-se do peso da amostra saturada o peso da amostra após a drenagem em determinada tensão e dividindo-se pelo volume da amostra indeformada, multiplicando por 100 , obtém-se o volume de vazios em percentagem. Assim, o volume de vazios drenados durante cada tensão pôde ser calculado.

Devido ao monitoramento do conteúdo de água do solo nos tratamentos T1 e T6 e por meio das equações ajustadas entre o conteúdo de água e a resistência do solo à penetração e o volume de vazios (Figura 1), nas tensões de 10,60, 100,330, 600, 1.000 e $3.000 \mathrm{hPa}$, foi possível estimar a variação da resistência do solo à penetração e do volume de vazios durante o experimento nesses tratamentos.

Para a determinação do intervalo hídrico ótimo (IHO), na profundidade de $0-0,30 \mathrm{~m}$, a curva de retenção de água no solo foi ajustada pelo modelo não linear empregado por Silva et al. (1994), na forma log-transformada, descrita a seguir: 
Quadro 1. Valores médios e erros-padrão da macroporosidade e densidade do solo nos diferentes níveis de compactação e profundidades do Latossolo Vermelho de textura média

\begin{tabular}{|c|c|c|c|c|c|c|}
\hline \multirow{2}{*}{ Profundidade } & \multicolumn{6}{|c|}{ Nivel de compactação } \\
\hline & $\mathbf{T}_{1}$ & $\mathbf{T}_{2}$ & $\mathbf{T}_{3}$ & $\mathbf{T}_{4}$ & $\mathbf{T}_{5}$ & $\mathbf{T}_{6}$ \\
\hline $\mathrm{cm}$ & \multicolumn{6}{|c|}{ Macroporosidade $\left(\mathrm{m}^{3} \mathrm{~m}^{-3}\right)^{(1)}$} \\
\hline $0-10$ & $0,16 \pm 0,05$ & $0,14 \pm 0,03$ & $0,12 \pm 0,04$ & $0,09 \pm 0,02$ & $0,08 \pm 0,01$ & $0,07 \pm 0,01$ \\
\hline $10-20$ & $0,15 \pm 0,03$ & $0,13 \pm 0,02$ & $0,11 \pm 0,01$ & $0,12 \pm 0,04$ & $0,13 \pm 0,02$ & $0,08 \pm 0,03$ \\
\hline $20-30$ & $0,16 \pm 0,04$ & $0,14 \pm 0,03$ & $0,11 \pm 0,02$ & $0,15 \pm 0,04$ & $0,14 \pm 0,02$ & $0,11 \pm 0,04$ \\
\hline \multirow[t]{2}{*}{ Média } & $0,16 \pm 0,01$ & $0,14 \pm 0,01$ & $0,12 \pm 0,01$ & $0,12 \pm 0,01$ & $0,12 \pm 0,01$ & $0,09 \pm 0,01$ \\
\hline & \multicolumn{6}{|c|}{ Densidade do solo $\left(\mathrm{kg} \mathrm{dm}^{-3}\right)$} \\
\hline $0-10$ & $1,34 \pm 0,08$ & $1,34 \pm 0,07$ & $1,40 \pm 0,10$ & $1,53 \pm 0,04$ & $1,52 \pm 0,04$ & $1,46 \pm 0,06$ \\
\hline $10-20$ & $1,37 \pm 0,05$ & $1,35 \pm 0,04$ & $1,42 \pm 0,03$ & $1,47 \pm 0,03$ & $1,40 \pm 0,05$ & $1,47 \pm 0,06$ \\
\hline $20-30$ & $1,36 \pm 0,05$ & $1,37 \pm 0,04$ & $1,42 \pm 0,06$ & $1,37 \pm 0,08$ & $1,41 \pm 0,05$ & $1,42 \pm 0,08$ \\
\hline Média & $1,35 \pm 0,01$ & $1,35 \pm 0,01$ & $1,41 \pm 0,01$ & $1,46 \pm 0,02$ & $1,45 \pm 0,01$ & $1,45 \pm 0,01$ \\
\hline
\end{tabular}

(1) Determinação realizada no conteúdo de água retida na capacidade de campo $(100 \mathrm{hPa})$. T1= solo preparado (escarificação e gradagem), sem tráfego de tratores; $\mathrm{T} 2=$ uma passada do trator de $4 \mathrm{t}$; $\mathrm{T} 3=$ uma passada do trator de $6 \mathrm{t}$; $\mathrm{T} 4=$ duas passadas do trator de $6 \mathrm{t}$; T5= quatro passadas do trator de $6 \mathrm{t}$; e T6: oito passadas do trator de $6 \mathrm{t}$.
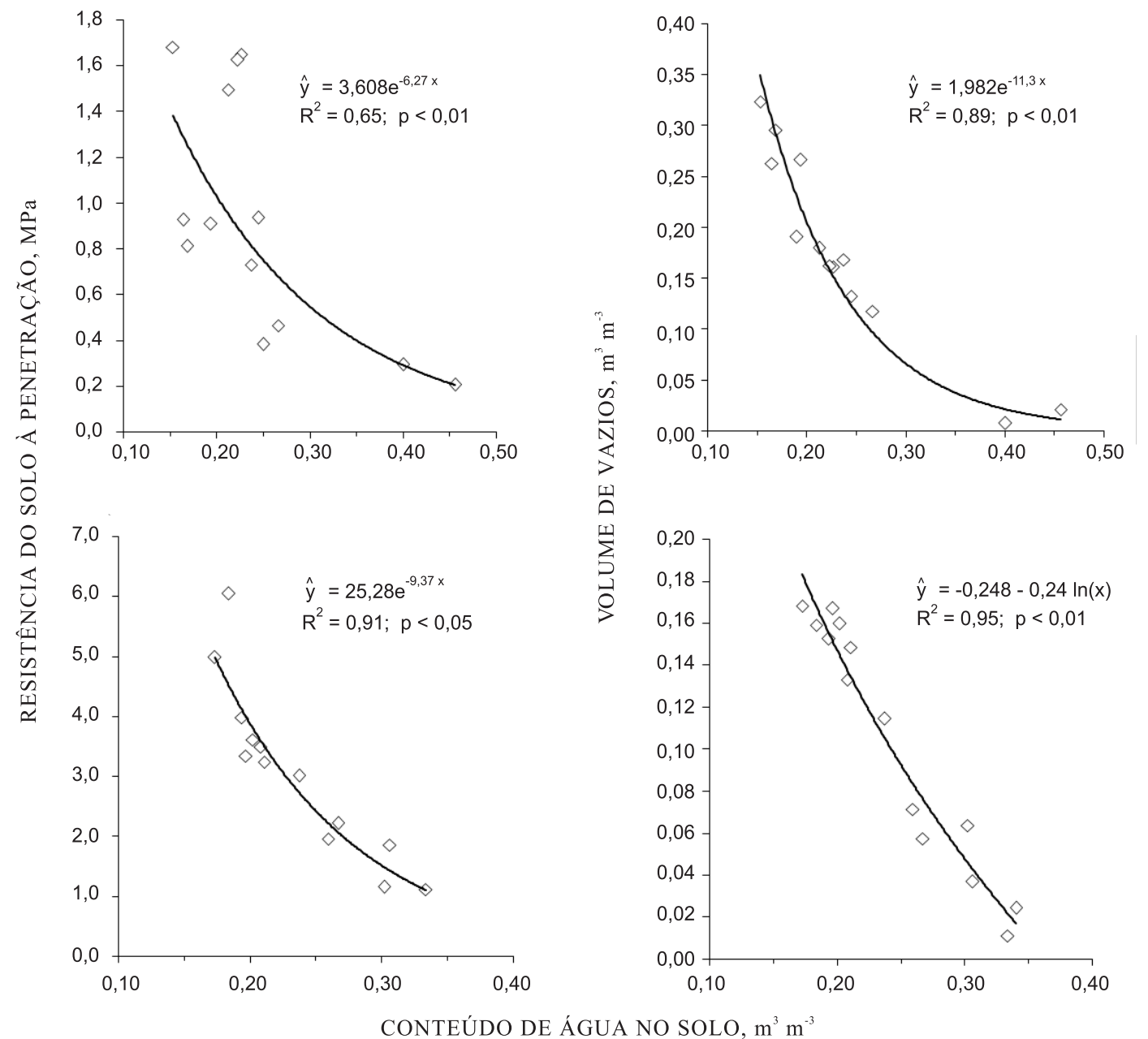

Figura 1. Regressão entre o conteúdo de água volumétrico e a resistência do solo à penetração (a) e volume de vazios (b) de um Latossolo Vermelho para a profundidade de 10-20 cm, para os tratamentos T1 (solo preparado e sem tráfego de máquinas) e T6 (solo preparado e submetido a oito passadas de um trator de $6 \mathrm{t})$. 


$$
\ln \theta=\ln \mathrm{a}+\mathrm{b} \ln \mathrm{Ds}+\mathrm{c} \ln \psi
$$

em que $\theta$ é o conteúdo volumétrico de água $\left(\mathrm{m}^{3} \mathrm{~m}^{-3}\right)$; Ds, a densidade do solo $\left(\mathrm{kg} \mathrm{dm}^{-3}\right) ; \psi$, a tensão de água no solo (hPa); e a, b, c, os coeficientes obtidos por meio do ajuste do modelo.

A partir dos coeficientes estimados pela equação 1, aplicou-se o antilogaritmo e foram obtidos os valores estimados das propriedades físicas. Assim, assumindose o conteúdo de água na capacidade de campo equivalente à tensão de $100 \mathrm{hPa}$ e o ponto de murcha permanente de $15.000 \mathrm{hPa}$, o $\theta_{\mathrm{CC}}$ e $\theta_{\mathrm{PMP}}$ foram estimados pelas equações (2) e (3), respectivamente, obtidas da equação (1), a seguir:

$$
\begin{gathered}
\theta_{\mathrm{CC}}=\exp ^{\mathrm{a}} \mathrm{Ds}^{\mathrm{b}} 100^{\mathrm{c}} \\
\theta_{\mathrm{PMP}}=\exp ^{\mathrm{a}} \mathrm{Ds}^{\mathrm{b}} 15.000^{\mathrm{c}}
\end{gathered}
$$

A curva de resistência do solo à penetração $(\mathrm{RP})$ foi ajustada utilizando o modelo não linear proposto por Busscher (1990), na forma log-transformada:

$$
\ln R P=\ln d+e \ln \theta+f \ln D s
$$

O conteúdo de água a partir do qual a resistência do solo à penetração é limitante foi obtido pela equação (5), derivada da equação (4):

$$
\theta_{\mathrm{RP}}=\left(\left(\mathrm{RP}_{\text {crit }}\right) /\left(\exp ^{\mathrm{d}}\left(\mathrm{Ds}^{\mathrm{e}}\right)\right)\right)^{1 / \mathrm{f}}
$$

A resistência do solo à penetração crítica $\left(R P_{\text {crit }}\right)$ no IHO foi obtida por meio da regressão entre a produtividade de grãos do milho e os diferentes níveis de compactação do solo, sendo o valor obtido de 2,15 MPa.

O conteúdo de água em que a porosidade de aeração é igual a $10 \%\left(\theta_{\mathrm{PA}}\right)$ foi calculado pela equação (6):

$$
\theta_{\mathrm{PA}}=\mathrm{PT}-0,1
$$

em que PT representa a porosidade total determinada nas amostras indeformadas do solo, $\mathrm{em} \mathrm{m}^{3} \mathrm{~m}^{-3}$.

A densidade relativa do solo ou grau de compactação (Dsr) foi obtida pela divisão da densidade do solo pela densidade de referência (ou densidade do solo máxima), determinada por meio do ensaio de Proctor, multiplicando-se por 100, para expressar o resultado em percentagem.

Para determinação da condutividade hidráulica saturada do solo nos tratamentos $\mathrm{T} 1$ e T6, foram realizados três pontos por parcela, utilizando o permeâmetro (2800 KI Guelph Permeameter) instalado a $10 \mathrm{~cm}$ de profundidade e submetido a duas cargas hidráulicas (3 e $6 \mathrm{~cm}$ de coluna de água). As leituras foram realizadas por meio do nível da coluna de água presente no aparelho, e, a partir do momento da estabilização das leituras, utilizou-se a média das três últimas e calculou-se a condutividade hidráulica saturada $\left(\mathrm{C}_{\mathrm{hs}}\right)$ de acordo com a seguinte expressão:

$$
\mathrm{C}_{\mathrm{hs}}=\left\{\left[(0,0041)(32,39)\left(\mathrm{x}_{1}\right)\right\}-\left[(0,0054)(35,39)\left(\mathrm{x}_{2}\right)\right]\right\} \text { fc }(7)
$$

em que $\mathrm{x}_{1}$ representou a média das três últimas leituras com carga hidráulica de $6 \mathrm{~cm}$ de coluna de água, em $\mathrm{cm} \mathrm{s}^{-1} ; \mathrm{x}_{2}$, a média das três últimas leituras com carga hidráulica de $3 \mathrm{~cm}$ de coluna de água, em $\mathrm{cm} \mathrm{s}^{-1}$; e fc, o fator de conversão para $\mathrm{mm} \mathrm{h}^{-1}$.

No estádio do pendoamento da cultura do milho foram retiradas três amostras por parcela, utilizandose um trado amostrador descrito em Fujiwara et al. (1994), distanciadas de $20 \mathrm{~cm}$ do eixo principal das plantas de milho, nas profundidades de 0-10, 10-20 e $20-30 \mathrm{~cm}$. As imagens das raízes foram digitalizadas em um scanner de leitura ótica, na resolução de $400 \mathrm{dpi}$, fornecendo o diâmetro médio $(\mathrm{mm})$ e o comprimento das raízes $(\mathrm{cm})$ pelo software Delta- $\mathrm{T}$ Scan; a densidade do comprimento radicular $\left(\mathrm{cm} \mathrm{cm}^{-3}\right)$ foi determinanda por meio da divisão do comprimento radicular pelo volume de solo coletado. Na sequência, as amostras foram secas em estufa a $65^{\circ} \mathrm{C}$ até massa constante, para determinação da massa de matéria seca das raízes por amostra (g), que foi dividida pelo volume de solo coletado, obtendo-se a massa de matéria seca das raízes por volume de solo $\left(\mathrm{mg} \mathrm{cm}^{-3}\right)$. Quando a umidade dos grãos foi inferior a $25 \%$, foram colhidas as espigas de duas linhas úteis de $2,0 \mathrm{~m}$, para debulha e determinação da massa de grãos. A produtividade de grãos de milho foi obtida extrapolando-se a produção de grãos da área útil da parcela para um hectare, considerando-se a umidade-padrão de $13 \%$.

Os dados do sistema radicular foram submetidos aos testes de Shapiro Wilk e Levene, ambos a $5 \%$, para verificação da normalidade dos resíduos e homocedasticidade das variâncias, respectivamente. Todas as variáveis do trabalho apresentaram distribuição normal e homocedasticidade, não havendo a necessidade de transformação dos dados.

As médias das cultivares foram comparadas pelo teste de Tukey a $5 \%$. Para o fator compactação do solo, realizou-se análise por regressão polinomial; sendo o teste $\mathrm{F}$ da variância da regressão significativo a $5 \%$, selecionaram-se modelos, adotando-se como critérios o maior $\mathrm{R}^{2}$ e a significância de $5 \%$ dos coeficientes da equação.

\section{RESULTADOS E DISCUSSÃO}

Pelo intervalo hídrico ótimo (IHO), pôde-se verificar que o aumento da Ds influenciou positivamente a variação do conteúdo de água disponível do solo [conteúdo de água na capacidade de campo $\left(\theta_{\mathrm{CC}}\right)-$ conteúdo de água no ponto de murcha permanente $\left.\left(\theta_{\mathrm{PMP}}\right)\right]$, concordando com Tormena et al. (1998) e Freddi (2007). Esse fato é justificado pela redução da macroporosidade e redistribuição dos tamanhos dos poros (Figura 2). 


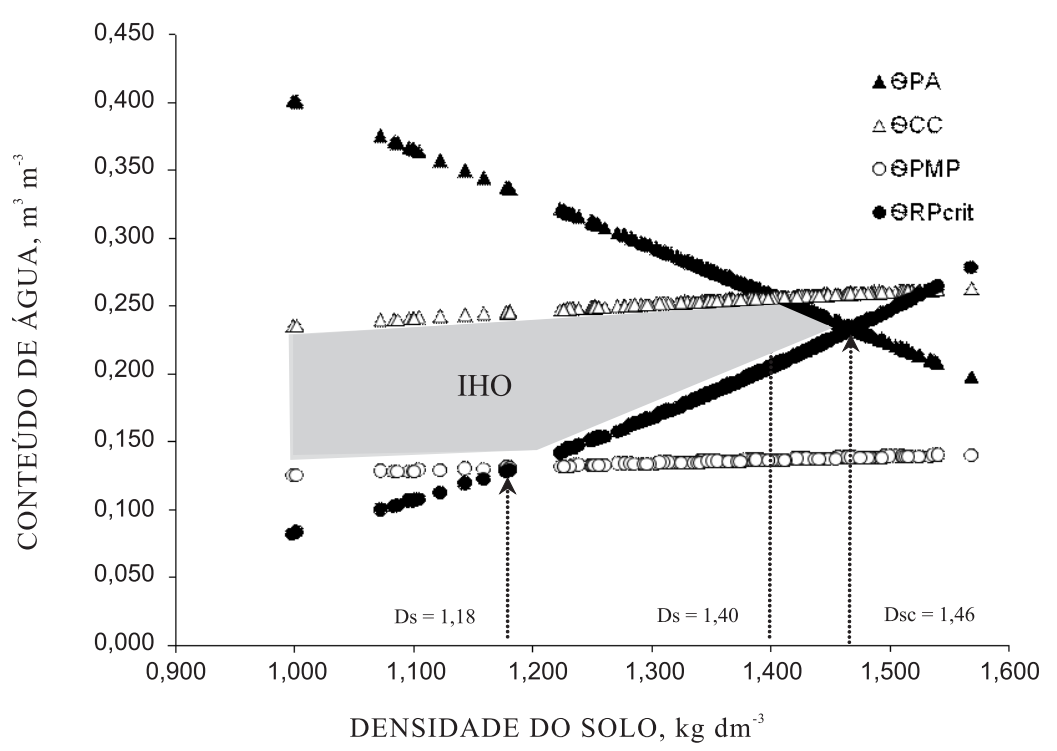

Figura 2. Variação do conteúdo de água volumétrico $(\theta)$ com a densidade do solo, para limites críticos da porosidade de aeração $\left(\theta_{\mathrm{PA}}\right)$, capacidade de campo $\left(\theta_{\mathrm{CC}}\right)$, resistência do solo à penetração de $2,15 \mathrm{MPa}$ $\left(\theta_{\mathrm{RP} \text { crit }}\right)$ e ponto de murcha permanente $\left(\theta_{\mathrm{PMP}}\right)$ no Latossolo Vermelho distrófico típico. IHO: intervalo hídrico ótimo; Ds: densidade do solo; Dsc: densidade crítica do solo, na profundidade de 0-30 cm.

A variação da Ds teve grande impacto sobre o conteúdo de água a partir do qual a resistência do solo à penetração é limitante $\left(\theta_{\mathrm{RP}}\right)$. $\mathrm{O} \theta_{\mathrm{RP}}$ substituiu o $\theta_{\mathrm{PMP}}$ no valor de $\mathrm{Ds} \geq 1,18 \mathrm{~kg} \mathrm{dm}^{-3}$; já na parte superior do IHO, a diminuição do $\theta_{\mathrm{PA}}$ pelo aumento da Ds também alcançou valores restritivos ao IHO, porém substituiu o $\theta_{\mathrm{CC}}$ apenas quando a $\mathrm{Ds}$ foi maior ou igual a $1,40 \mathrm{~kg} \mathrm{dm}^{-3}$. Esses resultados discordam dos obtidos por Tormena et al. (1998, 1999), Beutler et al. (2004) e Freddi (2007), para os quais, em solos tropicais, o IHO é limitado na parte superior pelo conteúdo de água na capacidade de campo e, na parte inferior, pela resistência do solo à penetração (Figura 2).

A densidade do solo crítica (Dsc) foi definida, segundo Silva et al. (1997), como aquela em que o IHO é igual a zero, ou seja, aquela na qual o limite inferior cruza com o limite superior do intervalo, a partir da qual ocorreriam limitações severas ao desenvolvimento das plantas. Nesse solo, a Dsc foi de $1,46 \mathrm{~kg} \mathrm{dm}^{-3}$, e a partir da Ds de $1,18 \mathrm{~kg} \mathrm{dm}^{-3}$, na parte inferior do IHO, a resistência do solo à penetração já seria restritiva para o crescimento do milho se o conteúdo de água do solo permanecesse abaixo do $\theta_{\mathrm{RP}}$, assim como, na parte superior do IHO, a partir da Ds de $1,40 \mathrm{~kg} \mathrm{dm}^{-3}$, se o conteúdo de água permanecesse acima do $\theta_{\mathrm{PA}}$, ocorreria limitação de aeração para o sistema radicular do milho (Figura 2). A Dsc determinada no IHO representou densidade relativa de $92 \%$ da densidade do solo máxima alcançada no ensaio de Proctor. Para Freddi (2007), a densidade relativa correspondente à Dsc do IHO para os Latossolos Vermelho de textura média e argilosa foi de 78 e $80 \%$, respectivamente.
Essa diferença na densidade relativa pode ser atribuída à irrigação, pois nos experimentos conduzidos por Freddi (2007), em Latossolos com diferentes texturas, a densidade relativa destes foi semelhante, provavelmente por não serem irrigados. Possivelmente, a maior densidade relativa crítica encontrada no experimento para o milho, seja devido à menor resistência do solo à penetração, a qual é atribuída ao conteúdo de água que se manteve mais elevado devido à irrigação, pois, segundo Almeida et al. (2008), há diminuição exponencial da resistência do solo à penetração com o incremento no conteúdo de água no solo. Em razão desse fato, o IHO foi mais amplo, sendo possível maior compactação do solo, sem restrições às plantas.

O crescimento das plantas é menos restrito dentro dos limites do IHO, conforme Silva et al. (1997). Assim, a magnitude do IHO pode ser utilizada como um diagnóstico da frequência com que a estrutura do solo determina o conteúdo de água limitante ao crescimento das plantas. Nesse contexto, todos os tratamentos apresentariam restrição pela resistência do solo à penetração (Figura 2), já que todos mostraram Ds acima de $1,18 \mathrm{~kg} \mathrm{dm}^{-3}$ (Quadro 1). Entretanto, os tratamentos T1 e T2 não apresentariam limitações impostas pela aeração do solo por terem Ds abaixo de $1,40 \mathrm{~kg} \mathrm{dm}^{-3}$. Para os tratamentos T4, T5 e T6, mesmo que o conteúdo de água ficasse sempre na capacidade de campo, haveria restrições pela $\mathrm{RP} e$ aeração do solo, por apresentarem Ds igual ou superior à Dsc de $1,46 \mathrm{~kg} \mathrm{dm}^{-3}$.

O conteúdo de água do solo encontra-se muitas vezes abaixo da capacidade de campo $(100 \mathrm{hPa})$ durante o 
ciclo das culturas, o que pode ser verificado na figura 3 , em que a $\theta_{\mathrm{RP}}$, em solos compactados, torna-se o fator limitante ao crescimento das plantas até a Dsc no IHO; contudo, nota-se que o tratamento T6 apresentou tensões de água superiores às do tratamento T1 durante a maior parte do ciclo da cultura, nas
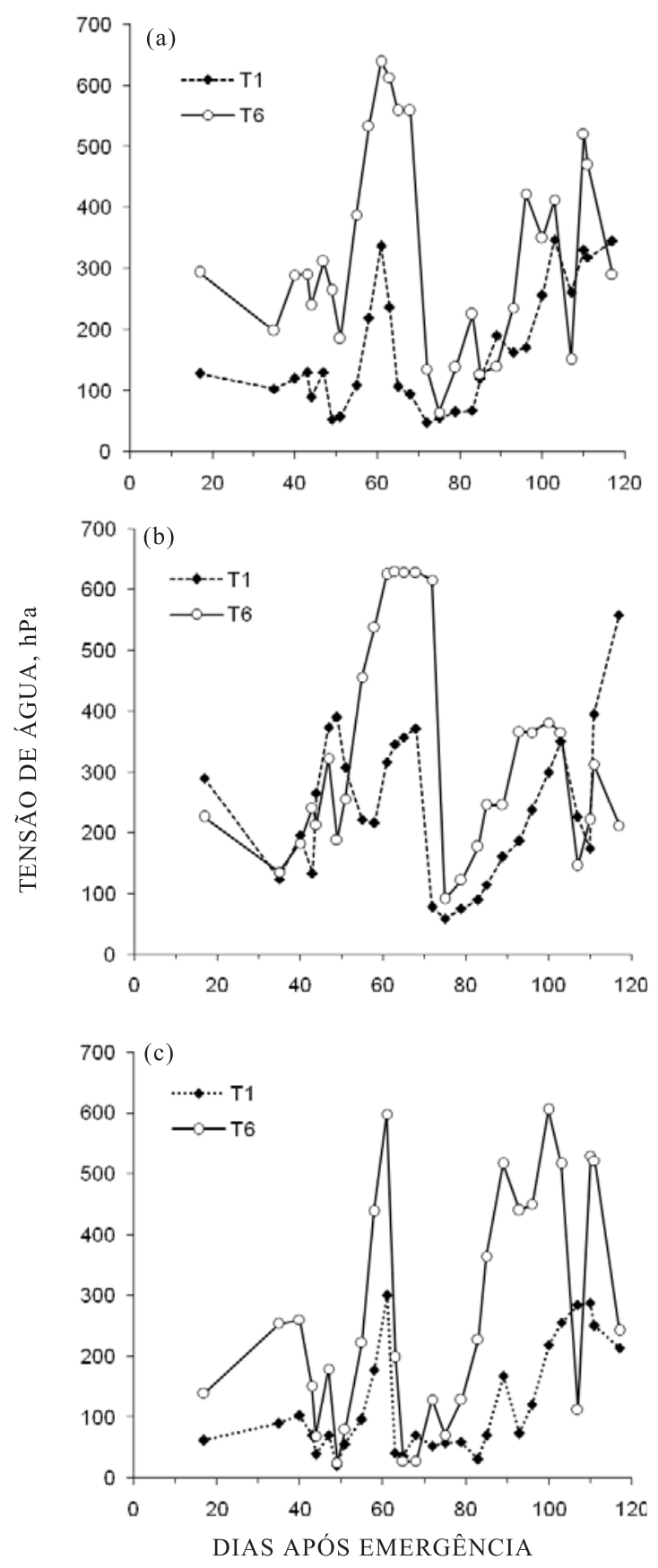

Figura 3. Variação da tensão de água do solo nas profundidades de 0-10 (a), 10-20 (b) e 20-30 cm (c) e níveis de compactação do Latossolo Vermelho durante o ciclo da cultura do milho. T1: solo preparado e sem tráfego de máquinas; T6: solo preparado e submetido a oito passadas de um trator de $6 \mathrm{t}$. profundidades de 0-10 e 10-20 cm. Já na profundidade de $20-30 \mathrm{~cm}$, as tensões apresentaram menor diferença; apenas em alguns períodos o tratamento $\mathrm{T} 1$ mostrou menor retenção de água do que o T6.

A maior tensão de água do solo no tratamento T6, durante o ciclo do milho, foi devido à menor infiltração de água na profundidade de $0-10 \mathrm{~cm}$ desse tratamento (Figura 4), promovendo menor capacidade de absorver a água da irrigação, culminando em escorrimento superficial. Silva \& Katto (1997), trabalhando em Latossolo Vermelho-Amarelo, constataram diferenças importantes na condutividade hidráulica saturada do solo sob plantio direto e sob manejo convencional, mostrando que pequenas diferenças na macroporosidade foram acompanhadas por elevadas diferenças de valores de condutividade hidráulica. A redução na macroporosidade tem grande efeito sobre a velocidade de infiltração de água e sobre o desenvolvimento radicular das plantas, por acarretar ao solo condições de baixa aeração, sobretudo em solos argilosos (Cintra \& Mielniczuk, 1983).

Observa-se também que, mesmo no tratamento T6, as tensões de água no solo não foram superiores a $600 \mathrm{hPa}$ (Figura 3), o que, segundo Azevedo (2002), não é limitante à absorção de água pela cultura do milho. Logo, pode-se afirmar que a tensão de água no solo não foi limitante para a absorção de água. Entretanto, verificou-se pelo IHO (Figura 2) que, mesmo que a tensão de água do solo ficasse na capacidade de campo (100 hPa), haveria restrições ao crescimento radicular pela elevada resistência do solo à penetração e deficiência na sua aeração para o tratamento T6, ou seja, a resistência do solo à penetração ficaria acima de 2,15 Mpa, e a porosidade

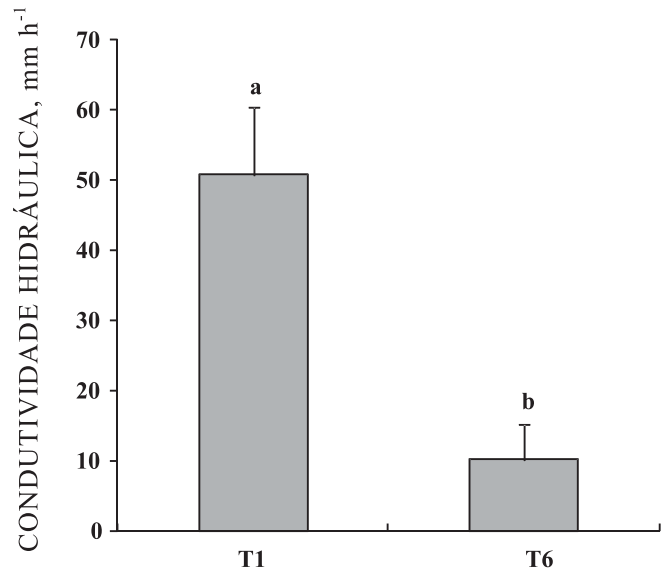

Figura 4. Condutividade hidráulica de um Latossolo Vermelho submetido a diferentes níveis de compactação. T1: solo preparado e sem tráfego de máquinas; T6: solo preparado e submetido a oito passadas de um trator de $6 \mathrm{t}$. As barras referem-se aos erros-padrão das médias. Médias seguidas da mesma letra não diferem estatisticamente pelo teste t a $5 \%$. 
de aeração, abaixo de $0,10 \mathrm{~m}^{3} \mathrm{~m}^{-3}$, mesmo que o solo permanecesse na capacidade de campo $(100 \mathrm{hPa})$, limitando a produtividade de milho, mesmo em condição de água disponível.

A incorporação da aeração do solo e da resistência do solo à penetração na definição do IHO, para o crescimento de plantas, tornou esse um indicador mais sensível às alterações da estrutura do solo do que o conteúdo de água disponível, como já verificado por Silva et al. (1994) e Freddi (2007). A faixa do conteúdo de água não limitante ao desenvolvimento do milho no IHO variou de 0 a $0,123 \mathrm{~m}^{3} \mathrm{~m}^{-3}$, enquanto para o conceito de água disponível foi de 0,109 a $0,123 \mathrm{~m}^{3} \mathrm{~m}^{-3}$, com o aumento da densidade do solo (Figura 2).

Observou-se maior variação da resistência do solo à penetração no tratamento T6 (Figura 5a) devido à sua maior variação do conteúdo de água durante o ciclo da cultura (Figura 3). A média da resistência do solo à penetração durante todo o período para os tratamentos T1 e T6 foi de 0,93 $\pm 0,03$ e $3,06 \pm 0,12 \mathrm{MPa}$, respectivamente. Logo, a média da resistência do solo à penetração no tratamento $\mathrm{T} 1$ ficou próxima à determinada na capacidade de campo de $0,87 \mathrm{MPa}$, na profundidade de $0-20 \mathrm{~cm}$, o que não foi observado no tratamento T6, que apresentou na capacidade de campo o valor de $2,15 \mathrm{MPa}$, devido aos valores de tensão de água superiores a $100 \mathrm{hPa}$ observados neste tratamento (Figura 5a).

As maiores tensões de água no tratamento T6, durante o ciclo do milho, podem ter resultado em maior resistência do solo à penetração para o desenvolvimento radicular. Contudo, observa-se (Figura 5b) que essa condição de solo mais seco proporcionou maior porosidade de aeração, sendo a média nos tratamentos T1 e T6 de 0,16 e 0,11 $\mathrm{m}^{3} \mathrm{~m}^{-3}$ respectivamente; na condição de capacidade de campo, seria de 0,13 e $0,06 \mathrm{~m}^{3} \mathrm{~m}^{-3}$, respectivamente. Dessa forma, pela definição do IHO, densidades acima de $1,40 \mathrm{~kg} \mathrm{dm}^{-3}$, para esse Latossolo Vermelho, resultariam numa porosidade de aeração abaixo de $0,10 \mathrm{~m}^{3} \mathrm{~m}^{-3}$ (limitante para o sistema radicular), com a elevação do conteúdo de água para capacidade de campo.

Assim, para esse solo, os resultados permitiram inferir que os limites do conteúdo de água propostos pelo IHO, em função da variação da densidade do solo, determinaram um indicador adequado e dinâmico para o monitoramento das restrições físicas impostas pela compactação do solo na cultura do milho. Logo, em áreas irrigadas, o IHO possibilita o monitoramento das condições físicas do solo, sem restrições ao crescimento das plantas por aeração e resistência do solo à penetração, por meio do controle do conteúdo de água do solo.

Nas três profundidades avaliadas, verificou-se que apenas nas profundidades de $10-20$ e $20-30 \mathrm{~cm}$ ocorreram diferenças significativas entre as cultivares para as variáveis diâmetro, nas duas profundidades, e densidade do comprimento radicular, na profundidade de $20-30 \mathrm{~cm}$. Houve diferenças nas
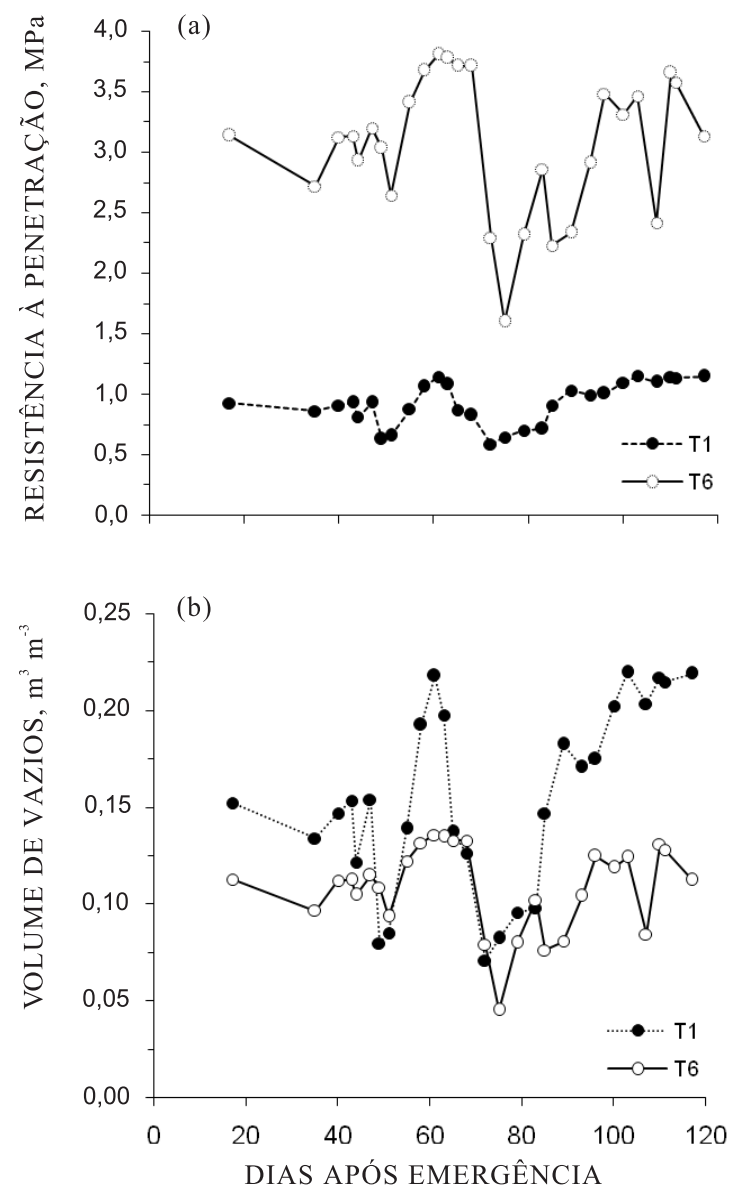

Figura 5. Variação da resistência do solo à penetração e volume de vazios na profundidade de 10-20 cm do Latossolo Vermelho durante o ciclo do milho para os tratamentos $\mathrm{T} 1$ (solo preparado e sem tráfego de máquinas) e T6 (solo preparado e submetido a oito passadas de um trator de $6 \mathrm{t}$ ).

características do sistema radicular, em todas as profundidades, conforme o nível de compactação do solo (Quadro 2).

O sistema radicular das duas cultivares, perante as restrições impostas pela compactação, foi semelhante (Quadro 2); não houve interação entre os fatores compactação e cultivar em nenhuma das profundidades.

Apesar do aumento da densidade do solo e da redução no volume de macroporos ocasionados pelo tráfego de tratores na profundidade de $0-10 \mathrm{~cm}$ (Quadro 1), houve aumento linear do diâmetro radicular. Também ocorreu aumento na densidade radicular até a resistência de $1,43 \mathrm{MPa}$, e, a partir dessa, houve diminuição da densidade das raízes (Figura 6). Segundo Silva \& Rosolem (2002), entre as modificações morfológicas nas raízes - provocadas pela restrição ao crescimento - estão o aumento do diâmetro e a diminuição do seu comprimento, tornando-as tortuosas. De acordo com Materechera 
Quadro 2. Valores de F calculados pela análise de variância para massa de matéria seca das raízes $\left.(\mathrm{mg} \mathrm{cm})^{-3}\right)$, diâmetro radicular $(\mathrm{mm})$ e densidade radicular $\left(\mathrm{cm} \mathrm{cm}^{-3}\right)$ nos diferentes níveis de compactação, cultivares e profundidades do Latossolo Vermelho

\begin{tabular}{|c|c|c|c|}
\hline Causa de variação & Matéria seca da raiz & Diâmetro radicular & Densidade radicular \\
\hline & & $0-10 \mathrm{~cm}$ & \\
\hline Compactação (C) & $2,880^{\mathrm{ns}}$ & $21,089 * *$ & $6,566^{* *}$ \\
\hline Cultivar (Cult) & $0,510^{\mathrm{ns}}$ & $8,731^{\mathrm{ns}}$ & $0,025^{\mathrm{ns}}$ \\
\hline C x Cult & $1,695^{\mathrm{ns}}$ & $0,996^{\text {ns }}$ & $1,255^{\mathrm{ns}}$ \\
\hline CV1 (\%) & 35,94 & 8,18 & 27,37 \\
\hline CV2 (\%) & 27,42 & 14,78 & 18,97 \\
\hline \multirow[t]{2}{*}{ Média geral } & 0,122 & 0,320 & 8,913 \\
\hline & & $10-20 \mathrm{~cm}$ & \\
\hline Compactação (C) & $4,221^{*}$ & $24,824^{* *}$ & $2,316^{\text {ns }}$ \\
\hline Cultivar (Cult) & $3,965^{\text {ns }}$ & $5,115^{\mathrm{ns}}$ & $11,266^{*}$ \\
\hline C x Cult & $0,608^{\mathrm{ns}}$ & $1,629^{\text {ns }}$ & $0,356^{\text {ns }}$ \\
\hline CV1 (\%) & 27,60 & 8,86 & 25,90 \\
\hline CV2 (\%) & 26,65 & 14,11 & 22,07 \\
\hline \multirow[t]{2}{*}{ Méd ia geral } & 0,110 & 0,371 & 6,533 \\
\hline & & $20-30 \mathrm{~cm}$ & \\
\hline Compactação (C) & $1,780^{\mathrm{ns}}$ & $9,065^{* *}$ & $2,474^{\mathrm{ns}}$ \\
\hline Cultivar (Cult) & $0,014^{\mathrm{ns}}$ & $15,661^{*}$ & $10,504^{*}$ \\
\hline C x Cult & $0,793^{\mathrm{ns}}$ & $1,237^{\mathrm{ns}}$ & $0,704^{\mathrm{ns}}$ \\
\hline CV1 (\%) & 30,92 & 8,83 & 23,12 \\
\hline CV2 (\%) & 47,04 & 12,60 & 25,72 \\
\hline Média geral & 0,089 & 0,394 & 5,401 \\
\hline
\end{tabular}

CV1(\%): coeficiente de variação referente ao fator compactação; CV2(\%): coeficiente de variação referente ao fator cultivar. * significativo a $5 \%, * *$ significativo a $1 \% \mathrm{e}^{\mathrm{ns}}$ não significativo.

et al. (1992), a compactação do solo pode promover o engrossamento das raízes, em razão de mudanças morfológicas e fisiológicas do sistema radicular, específicas de cada espécie ou cultivar, a fim de se adaptarem. Esse comportamento também foi observado por Freddi (2007), que verificou incrementos no crescimento radicular com o aumento da compactação do solo.

O mesmo comportamento da densidade radicular foi observado para massa de matéria seca das raízes, apesar de os coeficientes da regressão quadrática não serem significativos. Até uma passada do trator de $6 \mathrm{t}$ (T3), houve aumento do diâmetro e densidade das raízes, com o solo apresentando densidade de $1,40 \mathrm{~kg} \mathrm{dm}^{-3}$ e macroporosidade de $0,12 \mathrm{~m}^{3} \mathrm{~m}^{-3}$. A partir do tratamento com duas passadas do trator de 6 t (T4), verificou-se diminuição do volume de raízes e aumento do seu diâmetro; neste tratamento, a densidade do solo foi de $1,53 \mathrm{~kg} \mathrm{dm}^{-3}$ e a macroporosidade de $0,09 \mathrm{~m}^{3} \mathrm{~m}^{-3}$ (Quadro 1).

$\mathrm{O}$ aumento no diâmetro das raízes torna-se mais problemático, pois, de modo geral, a compactação também diminui o tamanho dos poros (Albuquerque \& Reinert, 2001), já que os macroporos constituem-se na rota principal do crescimento das raízes (Camargo
\& Alleoni, 1997). Observa-se também que a quantidade de macroporos abaixo de $0,10 \mathrm{~m}^{3} \mathrm{~m}^{-3}$, aparentemente limitante à aeração do sistema radicular, permitiu o desenvolvimento radicular, como observado por Mello Ivo \& Mielniczuk (1999) e Freddi (2007). Esses autores afirmam que esse desenvolvimento pode ser explicado pelo fato de esses valores terem sido obtidos com seus limites entre a macro e microporosidade, determinados na tensão de $60 \mathrm{hPa}$ (Mello Ivo \& Mielniczuk, 1999) e $100 \mathrm{hPa}$ (Freddi, 2007). Depois da drenagem e redistribuição da água no solo, a percentagem de poros livres de água e ocupados pelo ar provavelmente torna-se maior, o que pôde ser confirmado neste estudo (Figura 5b).

Quanto à profundidade de 10-20 cm, observou-se resposta linear entre a resistência do solo à penetração e a massa de matéria seca das raízes e o diâmetro radicular (Figura 7). Entretanto, não se verificaram modificações na densidade radicular nessa profundidade ( $\mathrm{p}>0,10)$. Mello Ivo \& Mielniczuk (1999) constataram maior raio médio das raízes de milho no plantio direto, que apresentou maior resistência do solo à penetração em relação ao preparo convencional. Meios rígidos, com resistências elevadas, levam as raízes a sofrerem deformações morfológicas 

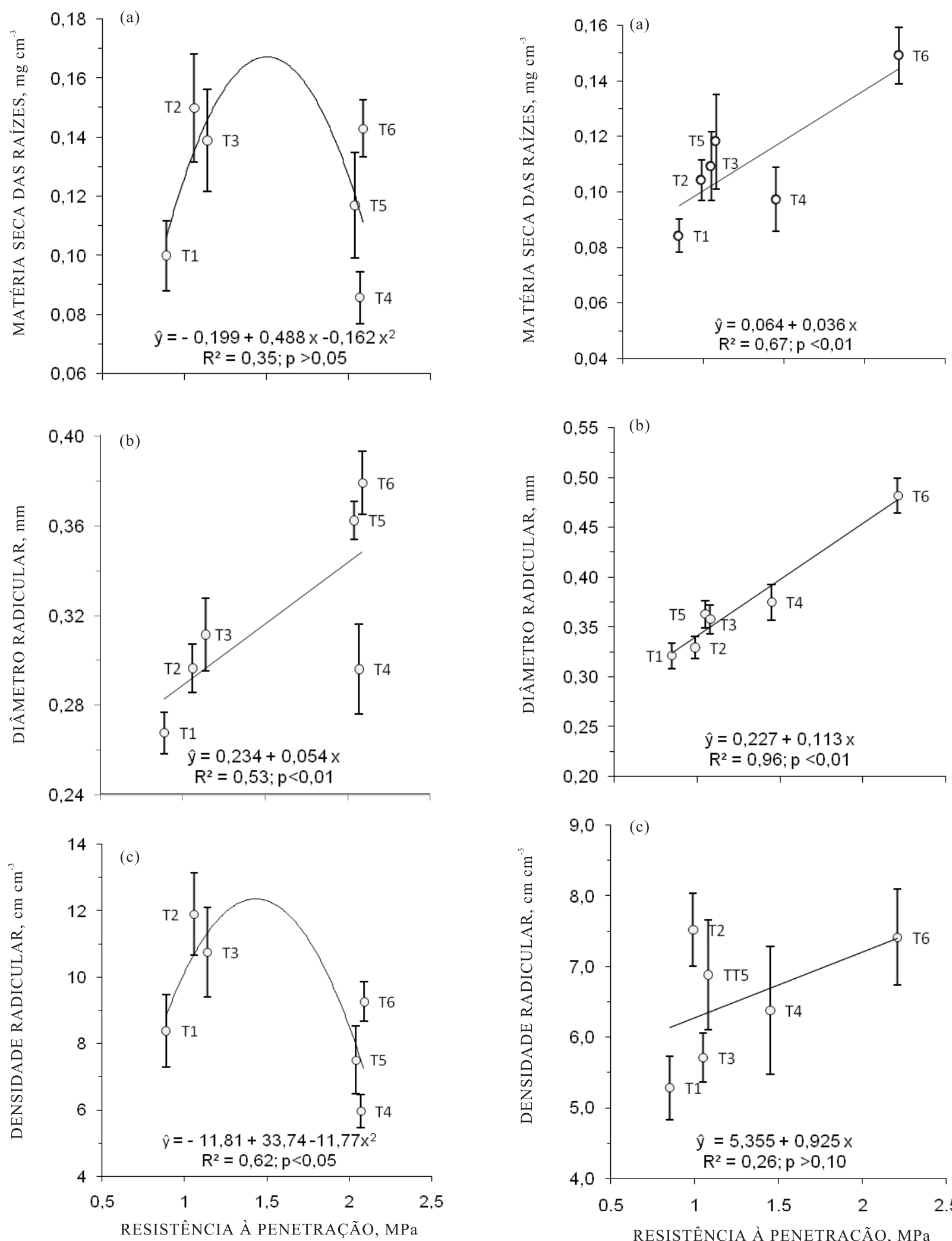

Figura 6. Regressão entre a resistência à penetração do Latossolo Vermelho na profundidade de 0$10 \mathrm{~cm}$ e a massa de matéria seca das raízes, diâmetro radicular e densidade do comprimento radicular. As barras referem-se aos erros-padrão das médias.

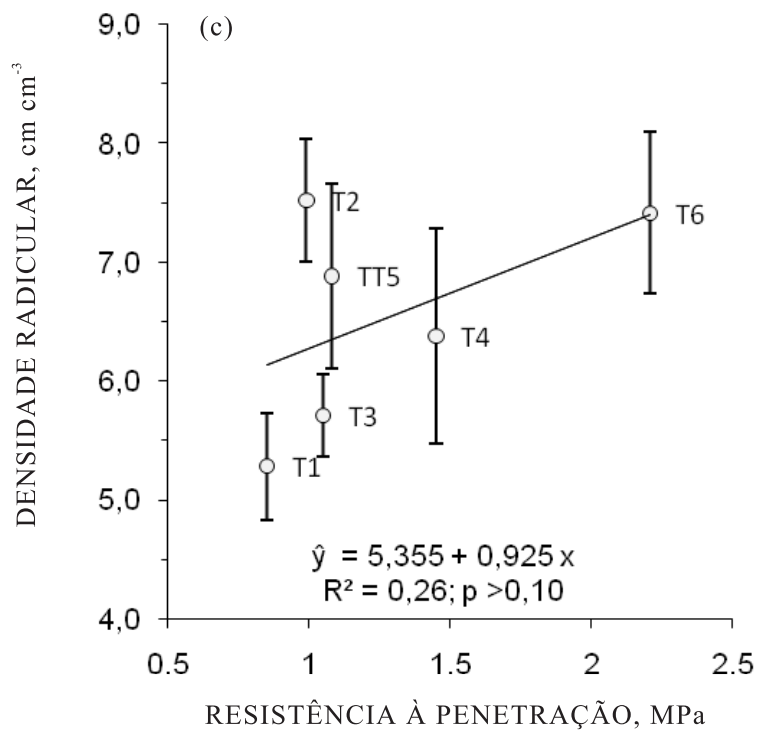

Figura 7. Regressão entre a resistência à penetração do Latossolo Vermelho na profundidade de 10$20 \mathrm{~cm}$ e a massa de matéria seca das raízes, diâmetro radicular e densidade do comprimento radicular. As barras referem-se aos erros-padrão das médias. 
exteriorizadas pelo aumento do raio. Segundo Bengough \& Mullins (1990), há principalmente aumento da espessura do córtex, devido ao aumento do número de células por unidade de comprimento de raiz.

A pressão de crescimento das raízes, segundo Camargo \& Alleoni (1997), depende da pressão de turgor das células do meristema radicular em processo de alongamento, bem como da área de contato da raiz sobre um agente rígido externo. Portanto, quanto maior o diâmetro da raiz, maior é a força exercida no processo de alongamento das células do meristema radicular, para penetração em determinada camada de solo. Concordando com as modificações das propriedades físicas pelo tráfego de tratores, verificouse que na profundidade de $20-30 \mathrm{~cm}$ não ocorreram alterações na morfologia do sistema radicular do milho (Figura 8), pois os coeficientes das regressões para massa de matéria seca, diâmetro e densidade radicular não foram significativos ( $p>0,05)$. Há confirmação, portanto, de que o tráfego de tratores de 4 e 6 t, na condição de capacidade de campo desse Latossolo Vermelho, não foi suficiente para alterar o crescimento radicular, assim como as propriedades físicas nessa profundidade.

Pela matriz de correlação (Quadro 3), observa-se que o aumento da massa de matéria seca das raízes resulta em aumento da densidade e diâmetro radicular, avaliados na profundidade de $0-0,20 \mathrm{~m}$; contudo, modificações no diâmetro radicular não proporcionaram alteração na densidade radicular.

As correlações entre a produtividade e os parâmetros do sistema radicular demonstraram que o aumento da massa de matéria seca das raízes, do diâmetro e da densidade radicular na profundidade de $0-20 \mathrm{~cm}$ é indicativo de perdas na produtividade de milho. Portanto, mesmo com a compactação superficial e o controle do conteúdo de água do solo por meio da irrigação, ocorreu modificação na morfologia do sistema radicular, o que resultou em perdas significativas na produtividade de grãos do milho.

Com relação às duas cultivares de milho, verificouse que o DKB 390 apresentou menor densidade radicular, independentemente das condições de compactação do solo, quando comparado à DAS 2B710 para a profundidade de 10-20 cm (Figura 9).

Já para profundidade de 20-30 cm, em que não se verificou interferência da compactação do solo, o híbrido DKB 390 apresentou raízes com maior diâmetro, porém menor quantidade de raízes por volume de solo, quando comparado ao DAS 2B710 (Figura 10). Logo, pode-se afirmar que o híbrido DKB 390 tem menor quantidade de raízes. Entretanto, são raízes de maior diâmetro, o que não resultou em melhoria na adaptação ao solo compactado, não concordando com os resultados de Kasperbauer
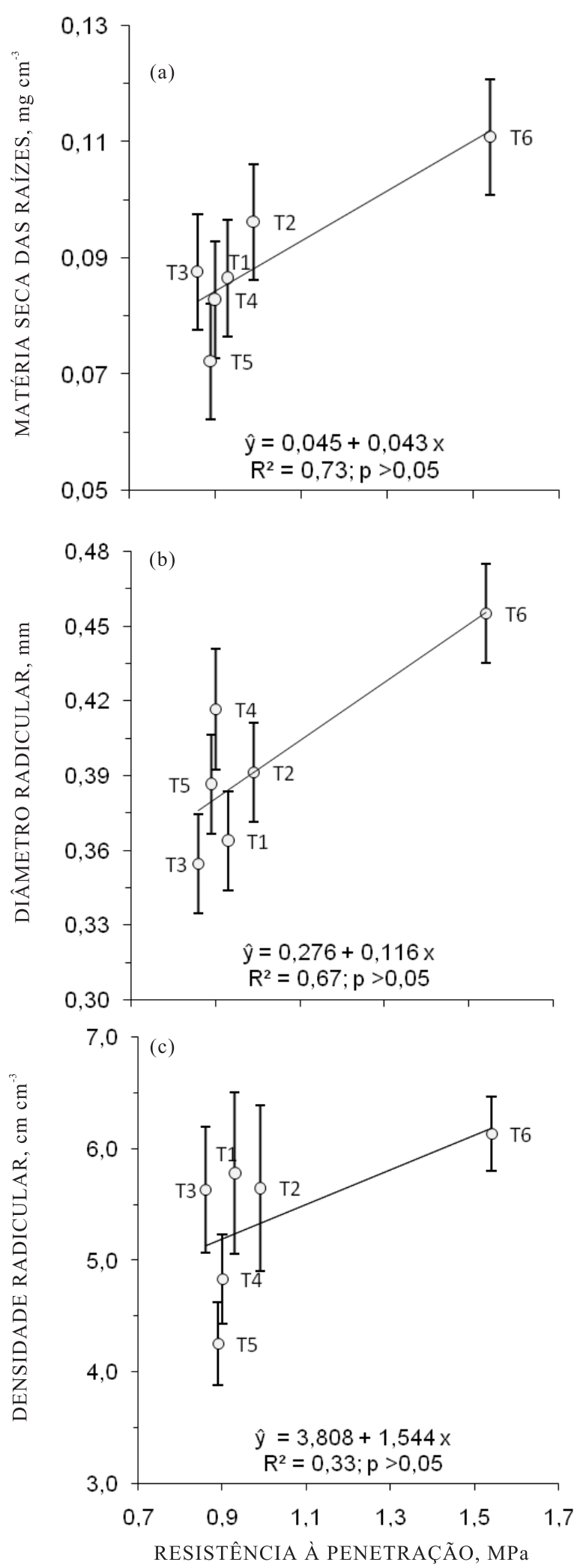

Figura 8. Regressão entre a resistência à penetração do Latossolo Vermelho na profundidade de 20 $30 \mathrm{~cm}$ e a massa de matéria seca das raízes, diâmetro radicular e densidade do comprimento radicular. As barras referem-se aos erros-padrão das médias. 
Quadro 3. Coeficientes de correlação entre as médias de massa de matéria seca das raízes, diâmetro e densidade radicular na profundidade de 0-20 cm e a produtividade de milho cultivado em um Latossolo Vermelho submetido a diferentes níveis de compactação

\begin{tabular}{lccc}
\hline Característica & Massa de matéria seca de raízes & Diâmetro radicular & Densidade radicular \\
\hline Diâmetro radicular & $0,34^{*}$ & & \\
Densidade radicular & $0,76^{* *}$ & $-0,06^{\mathrm{ns}}$ & $-0,30^{*}$ \\
Produtividade & $-0,35^{*}$ & $-0,29^{*}$ & \\
\hline
\end{tabular}

* significativo a $5 \%,{ }^{* *}$ significativo a $1 \% \mathrm{e}^{\mathrm{ns}}$ não significativo.

\& Busscher (1991), Yu et al. (1995), Bushamuka \& Zobel (1998), Borges et al. (1988) e Queiroz-Voltan et al. (2000), os quais observaram diferença nas respostas de variações genotípicas na habilidade das plantas em penetrar camadas compactadas. Provavelmente um dos fatores que podem explicar essa diferença nos resultados com a literatura seja a condução dos experimentos em vaso. Foi possível observar diferenças em algumas características do sistema radicular entre os híbridos. Contudo, verifica-se suscetibilidade à compactação do solo em ambos.

\section{CONCLUSÕES}

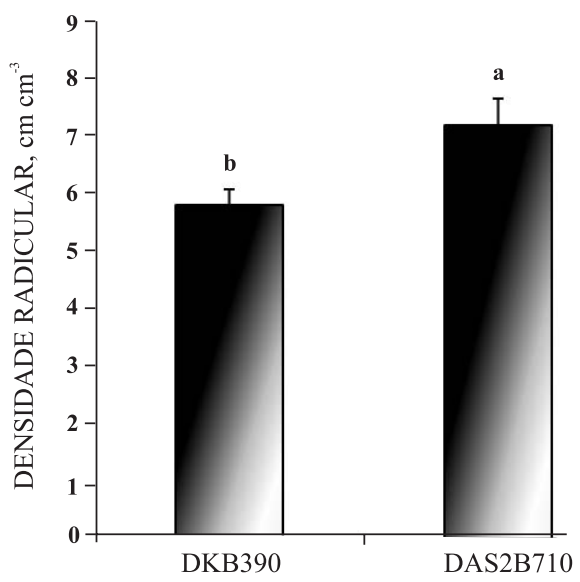

Figura 9. Densidade radicular das cultivares de milho DKB 390 e DAS 2 B710 na profundidade de 10-20 cm de um Latossolo Vermelho. As barras referem-se aos erros-padrão das médias.
1. O intervalo hídrico ótimo foi igual a zero quando o solo atingiu a densidade crítica de $1,46 \mathrm{~kg} \mathrm{dm}^{-3}$, correspondente a $92 \%$ da densidade máxima do solo.

2. A modificação na geometria porosa pela compactação do solo promoveu maior volume de água disponível no solo; todavia, há limitação pelo conteúdo de água em que a resistência do solo à penetração atinge 2,15 MPa e a porosidade de aeração é menor do que $0,10 \mathrm{~m}^{3} \mathrm{~m}^{-3}$, tornando esse maior volume de água indisponível às plantas.

3. Durante o ciclo da cultura do milho, a alteração da estrutura do solo pela compactação ocasionou maiores tensões de água devido à menor infiltração, em relação à condição de solo preparado, o que resultou em sua maior resistência à penetração, porém assegurou valores de porosidade de aeração superiores a $0,10 \mathrm{~m}^{3} \mathrm{~m}^{-3}$, não limitando a aeração do sistema radicular.
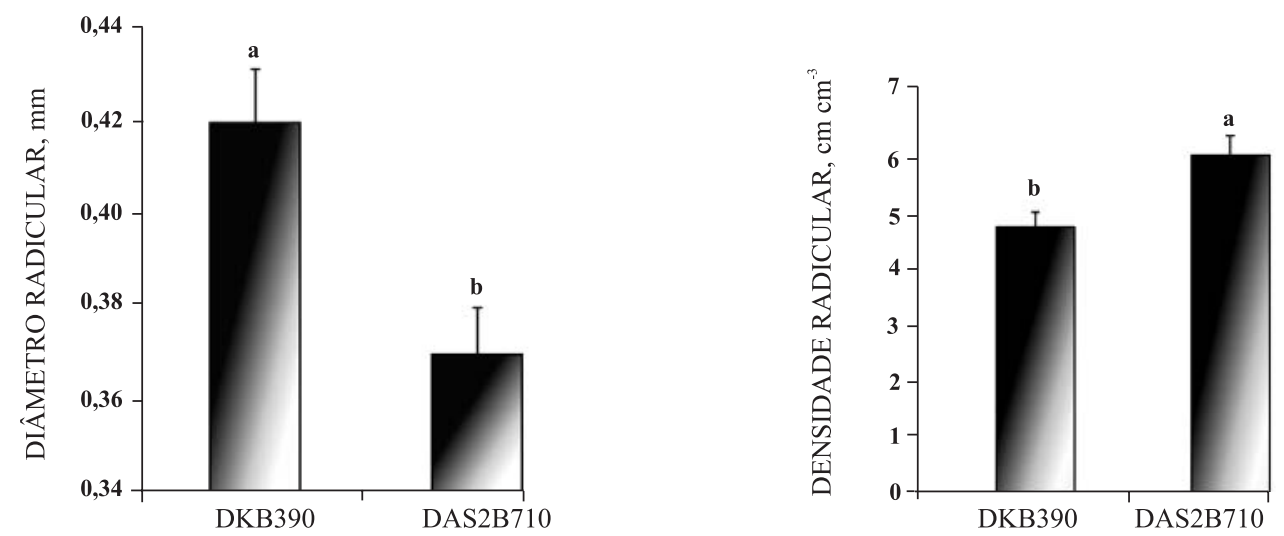

Figura 10. Diâmetro e densidade radicular das cultivares de milho DKB 390 e DAS $2 B 710$ na profundidade de 20-30 cm de um Latossolo Vermelho. As barras referem-se aos erros-padrão das médias. 
4. Com a compactação do solo, houve aumento da massa de matéria seca das raízes, da densidade do comprimento radicular e do diâmetro radicular; na profundidade de $0-10 \mathrm{~cm}$, o aumento da massa de matéria seca e da densidade radicular se dá até a resistência do solo à penetração de $1,23 \mathrm{MPa}$ e $1,43 \mathrm{MPa}$, respectivamente.

5. Houve correlação negativa entre a massa de matéria seca, a densidade e o diâmetro radicular com a produtividade do milho irrigado, mostrando que essas variáveis são bons indicadores da compactação do solo.

\section{AGRADECIMENTOS}

À Fundação de Amparo à Pesquisa do Estado de São Paulo (FAPESP), pela bolsa de estudos concedida ao primeiro autor. Os agradecimentos são extensivos ao Conselho Nacional de Desenvolvimento Científico e Tecnológico (CNPq), pela bolsa de produtividade em pesquisa ao segundo autor, e ao Pólo Alta Mogiana da Agência Paulista de Tecnologia para o Agronegócio (Apta), Colina (SP), pela concessão da área experimental.

\section{LITERATURA CITADA}

ALBUQUERQUE, J.A. \& REINERT, D.J. Densidade radicular do milho considerando os atributos de um solo com horizonte B textural. R. Bras. Ci. Solo, 25:539-549, 2001.

ALMEIDA, C.X.; CENTURION, J.F.; FREDDI, O.S.; JORGE, R.F. \& BARBOSA, J.C. Funções de pedotransferência para a curva de resistência do solo à penetração. R. Bras. Ci. Solo, 32:2235-2243, 2008.

ARAUJO, M.A.; TORMENA, C.A. \& SILVA, A.P. Propriedades físicas de um Latossolo Vermelho distrófico cultivado e sob mata nativa. R. Bras. Ci. Solo, 28:337-345, 2004.

AZEVEDO, J.A. Controle da irrigação para uso racional de água e de energia. Planaltina, Ministério da Agricultura, Pecuária e Abastecimento, 2002. (Comunica Técnico, 83)

BENGOUGH, A.G. \& MULLINS, C.E. Mechanical impendance to root growth: A review of experimental techniques and root growth response. J. Soil Sci., 41:341-358, 1990.

BENJAMIN, J.G.; NIELSEN, D.C. \& VIGIL, M.F. Quantifying effects of soil conditions on plant growth and crop production. Geoderma, 116:137-148, 2003.

BEUTLER, A.N.; CENTURION, J.F. \& SILVA, A.P. Intervalo hídrico ótimo e a produção de soja e arroz em dois Latossolos. Irriga, 9:181-192, 2004.

BEUTLER, A.N.; CENTURION, J.F.; CENTURION, M.A.P.C.; LEONEL, C.L.; JOÃO, A.C.G.S. \& FREDDI, O.S. Intervalo hídrico ótimo no monitoramento da compactação e da qualidade física de um Latossolo Vermelho cultivado com soja. R. Bras. Ci. Solo, 31:1223-1232, 2007.
BEUTLER, A.N.; CENTURION, J.F.; SILVA, A.P. \& BARBOSA, J.C. Intervalo hídrico ótimo e produtividade de cultivares de soja. R. Bras. Eng. Agríc. Amb., 10:639645,2006

BLAKE, G.R. \& HARTGE, K.H. Bulk density. In: KLUTE, A., ed. Methods of soil analysis: Part 1 -Physical and mineralogical methods. Madison, American Society of Agronomy, 1986. p.363-375.

BORGES, E.N.; NOVAIS, R.F.; FERNANDEZ, B. \& BARROS, N.F. Respostas de variedades de soja à compactação de camadas de solo. R. Ceres, 35:553-568, 1988.

BUSHAMUKA, V.N. \& ZOBEL, R.W. Differential genotypic and root type penetration of compacted soil layers. Crop Sci., 38:776-781, 1998.

BUSSCHER, W.J. Adjustment of flat-tipped penetrometer resistance data to a common water content. Am. Soc. Agric. Eng., 33:519-524, 1990.

CAMARGO, O.A. \& ALLEONI, L.R.F. Compactação do solo e o desenvolvimento das plantas. Piracicaba, Universidade Federal de Viçosa, 1997. 132p.

CINTRA, F.L.D. \& MIELNICZUK, J. Potencial de algumas espécies vegetais para recuperação de solos com propriedades físicas degradadas. R. Bras. Ci. Solo, 7:323327,1983

DANIELSON, R.E. \& SUTHERLAND, P.L. Porosity. In: KLUTE, A., ed. Methods of soil analysis: Part 1 -Physical and mineralogical methods. Madison, American Society of Agronomy, 1986. p.443-460.

FREDDI, O.S. Avaliação do intervalo hídrico ótimo em Latossolo Vermelho cultivado com milho. Jaboticabal, Faculdade de Ciências Agrárias e Veterinárias, 2007. 105p. (Tese de Doutorado)

FUJIWARA, M.; KURACHI, S.A.H.; ARRUDA, F.B.; PIRES, R.C.M. \& SAKAI, E. A técnica de estudo de raízes pelo método do trado. Campinas, Instituto Agronômico de Campinas, 1994. 9p. (Boletim Técnico, 153)

GARDNER, W.H. Water content. In: KLUTE, A., ed. Methods of soil analysis: Part 1 -Physical and mineralogical methods. Madison, American Society o Agronomy, 1986. p.493-541.

KASPERBAUER, M.J. \& BUSSCHER, W.J. Genotypic differences in cotton root penetration of a compacted subsoil layer. Crop Sci., 31:1376-1378, 1991.

KAY, B.D. Rates of changes of soil structure under different cropping systems. Adv. Soil Sci., 12:1-51, 1990.

KLEIN, V.A. \& CAMARA, R.K. Rendimento da soja e intervalo hídrico ótimo em Latossolo Vermelho sob plantio direto escarificado. R. Bras. Ci. Solo, 31:221-227, 2007.

KLUTE, A. Water retention: Laboratory methods. In: KLUTE, A., ed. Methods of soil analysis: Part 1 -Physical and mineralogical methods. Madison, American Society of Agronomy, 1986. p.635-660.

MATERECHERA, S.A.; ALSTON, A.M.; KIRBY, J.M. \& DEXTER, A.R. Influence of root diameter on the penetration of seminal roots into a compacted subsoil. Plant Soil, 144:297-303, 1992. 
MELLO IVO, W.M.P. \& MIELNICZUK, J. Influência da estrutura do solo na distribuição e na morfologia do sistema radicular do milho sob três métodos de preparo. R. Bras. Ci. Solo, 23:135-143, 1999.

QUEIROZ-VOLTAN, R.B.; NOGUEIRA, S.S.S. \& MIRANDA, M.A.C. Aspectos da estrutura da raiz e do desenvolvimento de plantas de soja em solos compactados. Pesq. Agropec. Bras, 35:929-938, 2000.

RIBEIRO, K.D. Influência da distribuição de vazios na condutividade hidráulica do solo saturado. Lavras, Universidade Federal de Lavras, 2005. 56p. (Tese de Mestrado)

SILVA, A.P.; KAY, B.D. \& PERFECT, E. Characterization of the least limiting water range. Soil Sci. Soc. Am. J., 58:1775-1781, 1994.

SILVA, A.P.; KAY, B.D. \& PERFECT, E. Management versus inherent soil properties effects on bulk density and relative compaction. Soil Till. Res., 44:81-93, 1997.
SILVA, C.L. \& KATTO, E. Efeitos do selamento superficial na condutividade hidráulica saturada da superfície de um solo sob cerrado. Pesq. Agropec. Bras., 32:213-220, 1997.

SILVA, R.H. \& ROSOLEM, C.A. Crescimento radicular de soja em razão da sucessão de cultivos e da compactação do solo. Pesq. Agropec. Bras., 37:855-860, 2002.

TORMENA, C.A.; SILVA, A.P. \& LIBARDI, P.L. Caracterização do intervalo hídrico ótimo de um Latossolo Roxo sob plantio direto. R. Bras. Ci. Solo, 22:573-581, 1998.

TORMENA, C.A.; SILVA, A.P. \& LIBARDI, P.L. Soil physical quality of a Brazilian Oxisol under two tillage systems using the least limiting water range approach. Soil Till. Res., 52:223-232, 1999.

YU, L.; RAY, J.D.; O‘TOOLE, J.C. \& NGUYEN, H.T. Use of wax-petrolatum layers for screening rice root penetration. Crop Sci., 35:684-687, 1995. 